\title{
HISTÓRIA ORAL E PATRIMÔNIO CULTURAL: PROJETO MEMÓRIA ORAL DO IPHAN ENTRE PRÁTICAS E DESAFIOS
}

Oral history and cultural heritage: Oral Memory Project of National Historical and Artistic Heritage Institute among practices and challenges

Historia oral y patrimonio cultural: Proyecto de Memoria Oral en Instituto Nacional de Patrimonio Histórico y Artístico entre prácticas y retos

FLÁVIA KLAUSING GERVÁSIO ${ }^{*}$ HILARIO FIGUEIREDO PEREIRA FILHO ${ }^{* * *}$ JOSEANE PAIVA MACEDO BRANDÃO ${ }^{* * * *}$

https://doi.org/10.1590/S2178-149420210308

Instituto do Patrimônio Histórico e Artístico Nacional, Mestrado Profissional em Preservação do Patrimônio Cultural Rio de Janeiro (RJ), Brasil.

*Doutora em Museologia e Patrimônio pela Universidade Federal do Estado do Rio de Janeiro (flaviakg@gmail.com)

(D) https://orcid.org/0000-0002-7093-4437

* Doutor em História pela Universidade Federal do Estado do Rio de Janeiro (hfpfilho@gmail.com)

(D) https://orcid.org/0000-0003-1114-9719

***Doutora em Sociologia pela Universidade Federal de Sergipe (joseanebrandao71@gmail.com)

(D) https://orcid.org/0000-0003-3747-4667

Artigo recebido em $1^{\circ}$ de maio de 2021 e aprovado para publicação em 23 de julho de 2021. 


\title{
RESUMO
}

0 artigo aborda a trajetória do Projeto Memória Oral do Instituto do Patrimônio Histórico e Artístico Nacional em três momentos diferentes: a fase preliminar das primeiras entrevistas realizadas na década de 1980; 0 segundo período, entre 2007 e 2020, quando houve a incorporação da metodologia de história oral no âmbito de um projeto de pesquisa formalmente estruturado; e o atual contexto, marcado substancialmente pela pandemia da COVID-19, que trouxe novas questões teórico-metodológicas de como desenvolver o projeto de forma propositiva em um cenário de adversidades.

PALAVRAS-CHAVE: Projeto; IPHAN; Memória; Entrevistas; História Oral.

\begin{abstract}
The article discusses the trajectory of the Oral Memory Project of the National Historical and Artistic Heritage Institute in three different moments: the preliminary phase of the first interviews conducted in the 1980s; the second period, between 2007 and 2020, when the methodology of oral history was incorporated into a formally structured research project; and the current context, marked substantially by the COVID-19 pandemic, which brings up new theoretical and methodological questions regarding how to develop the project purposefully in such an adverse scenario.
\end{abstract}

KEYWORDS: Project; IPHAN; Memory; Interviews; Oral History.

\section{RESUMEN}

El artículo analiza la trayectoria del Proyecto de Memoria Oral del Instituto Nacional de Patrimonio Histórico y Artístico en tres momentos diferentes: la fase preliminar de las primeras entrevistas realizadas en los años ochenta; el segundo período, entre 2007 y 2020, cuando la metodología de historia oral se incorporó a un proyecto de investigación formalmente estructurado; y el contexto actual, marcado sustancialmente por la pandemia COVID-19, que trae nuevas preguntas teóricas y metodológicas sobre cómo desarrollar el proyecto de manera intencionada en un escenario de adversidad.

PALABRAS Clave: Proyecto; IPHAN; Memoria; Entrevistas; Historia oral. 
osso olhar retrospectivo para as ações responsáveis pelas entrevistas no âmbito do
Instituto do Patrimônio Histórico e Artístico Nacional (IPHAN) está guiado por algumas intencionalidades, a começar pelo sentido de trajetória encampado em nossa análise. A ideia de tecer um possível enredo com iniciativas e propostas distanciadas temporalmente é característica das análises construídas a posteriori. Temos noção disso e explicitamos nosso referencial: apresentar o Projeto Memória Oral com base em suas características ao longo do tempo, além de assumi-lo como projeto de pesquisa em desenvolvimento no âmbito do Mestrado Profissional do IPHAN. A proposta de refletir sobre as iniciativas de realização de entrevistas na instituição traz nosso esforço de organizar essas experiências conforme balizas temporais construídas no tempo presente.

0 objetivo do artigo consiste em analisar criticamente aspectos de semelhanças, diferenças, continuidades, interrupções e rupturas entre três fases identificadas no Projeto Memória Oral do IPHAN. O período inaugural abrange as primeiras entrevistas realizadas de forma sistematizada no órgão preservacionista durante a década de 1980, quando os encontros eram registrados com o uso de gravadores de fitas cassete. A segunda fase, iniciada em 2007, propõe trabalhar com o legado de depoimentos e realizar novas entrevistas baseadas na metodologia da história oral. Já o terceiro período abrange o cenário atual, alicerçado pelas novas tecnologias em prol do fazimento de entrevistas, porém impactadas pelas dificuldades da pandemia da COVID-19.

Realizar um balanço das duas primeiras iniciativas do Projeto Memória Oral do IPHAN pode servir, também, para redimensionar os desafios contemporâneos. Se na década de 1980 o principal objetivo era registrar as memórias dos antigos funcionários, nos anos 2000 houve esforços de consolidar o acervo de fontes orais, articulados com a adoção da metodologia de história oral e a concomitante produção de conhecimento. Ainda que o Projeto sofra das intercorrências típicas do serviço público, acrescidas do momento disruptivo que todos nós sofremos no contexto pandêmico, revisitar os referidos períodos mostra-se como estratégia na proposição de novas abordagens. A perspectiva interdisciplinar, consonante com o Mestrado Profissional do IPHAN, pode ser uma forma interessante de estabelecer conexões com a metodologia de história oral, a qual se mostra continuamente aberta aos novos debates.

\section{A PIONEIRA SÉRIE DE ENTREVISTAS NA INVENTIVA DÉCADA DE 1980}

valorização do patrimônio cultural no contexto de redemocratização do país, nos anos
1980, época do surgimento desse projeto, esteve profundamente articulada com as disputas de memória na sociedade brasileira. Com o ressurgimento dos movimentos sociais, novos 
agentes, para além da burocracia e dos intelectuais, demandavam participação no campo das políticas patrimoniais, e o patrimônio passou a ter papel testemunhal das temporalidades que compõem as múltiplas experiências vividas individual e coletivamente na sociedade brasileira.

Noções como "participação da comunidade" e "direitos culturais" tornaram-se importantes para uma política cultural que se pretendia democrática. Nesse sentido, ocorreu uma reorientação dos discursos e estratégias das instituições associadas à preservação dos patrimônios culturais, que passaram a ser apropriadas como instrumentos de construção da cidadania e afirmação social da identidade de grupos que buscavam visibilidade e acesso a direitos. Com a junção da Secretaria do Patrimônio Histórico e Artístico Nacional (SPHAN) com a Fundação Nacional Pró-Memória, sob a direção de Aloísio Magalhães até seu falecimento em 1982, houve a ampliação e a diversificação dos quadros profissionais do órgão, que contribuíram para ampliar a noção de patrimônio e para uma representação mais plural da cultura brasileira.

As primeiras coletas sistematizadas de depoimentos de agentes que atuaram no campo do patrimônio, mais precisamente em interface com o IPHAN, iniciaram-se no ano de 1982. Ainda que conversas de corredor fizessem parte do cotidiano da instituição e que relatos recontados até mesmo fora do ambiente de trabalho fomentassem espécies de memórias coletivas da instituição (Halbwachs, 1990), a iniciativa de realizar entrevistas com antigos funcionários ocorreu durante o funcionamento concomitante da SPHAN e da Fundação Nacional Pró-Memória. Àquela época, Teresinha Marinho, bacharel e licenciada em Letras, trabalhava no Núcleo de Editoração da SPHAN/Pró-Memória, quando mobilizou esforços para tal empreitada, apoiada por colegas que deram suporte para a iniciativa.

Essas e outras informações acerca do nascedouro e do desenvolvimento do Projeto Memória Oral SPHAN/Pró-Memória não foram encontradas no Arquivo Central do IPHAN Seção Rio de Janeiro (ACl-RJ), principal e mais antigo acervo histórico da instituição. Eram os idos de 2007 quando o IPHAN completava 70 anos de vida e, nesse contexto de efemérides, houve um pedido por parte da presidência do órgão de que o Projeto fosse retomado depois de décadas de paralisação. Na ocasião, a equipe da Coordenação-Geral de Pesquisa e Documentação (COPEDOC) foi destacada para iniciar as pesquisas no acervo do ACl-RJ. Se por um lado, conforme já adiantamos, o escopo da memória de trabalho do Projeto Memória Oral SPHAN/Pró-Memória não foi localizado, por outro um rico e diversificado manancial de fontes orais aflorou como grande novidade para o acervo do Arquivo Central, até então conhecido por seus registros históricos textuais, iconográficos e cartográficos.

Ao lançar um olhar pormenorizado para o repertório de 27 entrevistas, a equipe do Projeto Memória Oral do IPHAN, coordenada pela historiadora Analucia Thompson, sistema- 
tizou fichas técnicas sobre essas fontes orais. A análise dos formatos e conteúdos produzidos por Teresinha Marinho pode ser sumarizada da seguinte maneira: 19 dos 27 entrevistados eram antigos funcionários do IPHAN, enquanto oito desenvolveram trabalhos no campo da cultura em interface com o patrimônio; as perguntas destacavam algum tipo de ação específica como obras de restauração, além da opinião do entrevistado sobre o primeiro diretor do IPHAN, Rodrigo Melo Franco de Andrade2; as pessoas escolhidas para conceder depoimentos eram agentes que haviam atuado nos primeiros distritos regionais da instituição, ou seja, Bahia, Minas Gerais, Pernambuco, São Paulo e a antiga sede no Rio de Janeiro; a maioria dos entrevistados tinha ocupado cargos de chefia, além de serem homens e profissionais aposentados de áreas tradicionalmente valorizadas na instituição, como Arquitetura, Restauração e Museologia (Thompson, 2009: 18-21).

Desejosos de saber os meandros por meio dos quais se estabeleceu a primeira fase do projeto, membros da equipe da COPEDOC entrevistaram Teresinha Marinho no ano de 2009. Munida de anotações em folhas manuscritas, a idealizadora do Memória Oral SPHAN/Pró-Memória complementou lacunas de informações não encontradas no acervo do ACl-RJ. Instada a falar sobre como surgiu a proposta de fazer as entrevistas, percebe-se que a narrativa adotada é marcada como um desdobramento das práticas de trabalho no Núcleo de Editoração:

Durante a pesquisa para aqueles dois livros sobre Dr. Rodrigo, comecei a perguntar tudo para o pessoal. E vi que as pessoas eram de primeira. Eu chamava lá na minha mesa. Por exemplo, Dona Judith Martins ${ }^{3}$ todo dia vinha para conversar e contar as histórias. De maneira que 0 folhetinho dela tinha muita coisa da história do patrimônio. [...]

A Dona Judith tinha oitenta anos. Ela foi secretária de Dr. Rodrigo e sabia de tudo e ajudava muito ele. De maneira que ela tinha conhecimento total e o pessoal todo respeitava muito. Ela me contava histórias e eu tomei nota disso e daquilo. Aí eu fiz duas ou três entrevistas e dei para João Leite, que gostou da ideia e disse: vamos fazer uma coleção (Marinho, 2009).

Sensibilizado pela proposta, o responsável pelo Núcleo de Editoração, João de Souza Leite, incorporou rapidamente os objetivos do Projeto Memória Oral SPHAN/Pró-Memória. Em entrevista realizada com o religioso Dom Clemente da Silva Nigra ${ }^{4}$ no ano de 1983, João Leite participou com Teresinha Marinho da dinâmica e revelou as principais intencionalidades ao entrevistado:

Agora nós estamos começando a implantar novamente a Revista do Patrimônio. Editamos um livro, aliás eu não sei se o senhor tem... Um livro de Mário de Andrade - a correspondência de Mário de Andrade a Dr. Rodrigo. E dentro desse programa específico, de onde saiu esse livro de Mário de Andrade, da correspondência de Mário para Dr. Rodrigo, nós estamos fazendo, sob a coordenação de Teresinha, um trabalho de história oral. Nós estamos documentando a 
história oral do Patrimônio, entrevistando pessoas que estiveram ligadas intimamente, fossem funcionários ou não do Patrimônio. Então já entrevistamos D. Judith, D. Lygia, Dr. Edgard, Dr. Alcides, Dr. Lucio, e temos ainda uma grande lista de nomes. Porque nos parece que através dessa documentação a gente complementa com o trabalho realizado nos arquivos, feito também por Teresinha, a gente vai ter, de fato, uma história mais abrangente do que era esse serviço, no âmbito federal. Então, nesse sentido, é que viemos the procurar, para ter o seu depoimento (Marinho, 1985).

Para além da informação de que a linha editorial do IPHAN se intensificou nos anos 1980, interessa sublinhar na fala de João Leite a menção ao termo "história oral". De fato, houve nesse contexto aumento significativo das práticas de entrevista no país, com destaque para o pioneirismo do Programa de História Oral do Centro de Pesquisa e Documentação de História Contemporânea do Brasil (CPDOC), da Fundação Getúlio Vargas (FGV), a partir de 1975. 0 panorama geral de abertura política após décadas do regime da ditadura civil militar, assim como o uso frequente dos gravadores portáteis e os debates acadêmicos em torno da história oral (Ferreira e Amado, 2006), foi outro fator que contribuiu para o aumento das iniciativas de produção de fontes orais, fosse nos grupos de pesquisa das universidades, fosse nas práticas de instituições e de grupos coletivos como sindicatos, partidos políticos e associações de moradores.

No caso específico do IPHAN, havia o interesse de ampliar o leque de informações acerca da instituição, que já vivia o ingresso de novos agentes desde a saída de Rodrigo Melo Franco de Andrade e sua rede de colaboradores. Os nomes referenciados na fala de João Leite são todos de atores que participaram ativamente do processo de consolidação do IPHAN nas primeiras décadas da instituição. Ao mesmo tempo em que são chamados em tom respeitoso pelos pronomes de tratamento, a não utilização de sobrenomes revela uma espécie de intimidade-cumplicidade com a própria história institucional. Além da já referenciada Judith Martins, foram citados Lygia Martins Costa ${ }^{5}$, Edgard Jacintho ${ }^{6}$, Alcides da Rocha Miranda ${ }^{7}$ e Lucio Costa8. A coleta de depoimentos teve, portanto, um sentido de complementar as fontes escritas identificadas, sendo possível constatar "o indício de uma falta" (Rousso, 1996) nos arquivos do IPHAN.

As entrevistas da primeira fase mostravam-se como ferramentas com as quais eram apreendidas informações num esforço de corroborar a narrativa institucional de grandes nomes responsáveis pela preservação do patrimônio cultural no país. Ao analisar as 27 entrevistas da década de 1980, Analucia Thompson tece um quadro geral com as principais características: a estrutura dos roteiros era de perguntas diretas e curtas, permitindo ao entrevistado discorrer de forma livre; as questões giravam em torno dos momentos iniciais da instituição, 
enfocando a contribuição do entrevistado para estabelecer condições de trabalho preservacionistas na região em que atuava; o tom das narrativas era memorialístico e não trazia à tona os conflitos cotidianos e institucionais; enalteciam-se personalidades de renome como Rodrigo Melo Franco de Andrade, além dos ocupantes de cargos de chefia na instituição; e havia um sentimento compartilhado de que, apesar das adversidades, a missão patrimonial era algo gratificante (Thompson, 2009: 19).

0 traço de informalidade foi uma constante nas 27 entrevistas, característica que quebrou certa rigidez dos documentos escritos da repartição. A experiência lançada na década de 1980 foi qualificada da seguinte forma pela nova equipe que assumiu os trabalhos quase trinta anos depois:

Apesar de não utilizar uma metodologia específica, com objetivos e procedimentos claramente definidos, as entrevistas realizadas pelo Projeto Memória Oral SPHAN/Pró-Memória, na década de 1980, devem ser entendidas como a primeira experiência em história oral no IPHAN. As condições para tal empreendimento já vinham sendo criadas desde meados da década de 1970, no que diz respeito ao campo da história oral (Thompson, 2010: 12).

Assim como a história oral inovou metodologicamente o campo historiográfico, sua prática inspirou a adoção de novas iniciativas nos procedimentos da pesquisa de caráter institucional. Ainda que tenha mantido o viés de entrevistar os agentes tidos como mais importantes do IPHAN, a opção de produzir fontes orais foi algo destacado para que outras histórias institucionais pudessem ser fomentadas. A plasticidade da oralidade dos artífices do patrimônio permitiu uma abordagem diferente dessas memórias, as quais poderiam passar despercebidas e desconhecidas com a hegemonia da palavra escrita na instituição.

As possibilidades do uso de entrevistas, como destaca Verena Alberti (1996), residem justamente na potencialidade da história oral de documentar as ações de constituição de memórias, aquilo que os entrevistados consideram como legítimo. Nesse caso, permitem mostrar como essas memórias sobre a criação e a consolidação do IPHAN se constituíram. "A meu ver, a grande riqueza da história oral é ela permitir investigações sobre como representações se tornam fatos - o que pressupõe um caráter 'acontecimental' da memória, para além de sua função de 'significar' o passado" (Alberti, 1996: 9).

Contudo, houve grande risco de se perderem as gravações das 27 entrevistas quando as fitas cassete permaneceram armazenadas sem o devido tratamento técnico. Não obstante as dificuldades e interrupções do serviço público, os registos orais perseveraram e, diante de um panorama favorável de maior valorização da pesquisa e da documentação, o Projeto Memória Oral do IPHAN pôde ser retomado. De quase esquecidas no acervo intermediário do Arquivo Central do IPHAN, as fontes orais foram alçadas a um novo patamar de destaque. 
Além da tarefa de gerenciar esses registros em termos arquivísticos, havia outros desafios que se apresentaram a partir da segunda fase do projeto: seria possível fazer uma história oral institucional com seus próprios servidores? Como articular um projeto adequado do ponto de vista teórico e metodológico, considerando-se a consolidação da história oral na historiografia e em outras áreas do conhecimento?

\section{MEMÓRIA ORAL DO IPHAN COMO PROJETO DE HISTÓRIA ORAL}

partir de 2007 houve a reunião de condições necessárias para o retorno das atividades
do Projeto Memória Oral: além das comemorações pelos 70 anos do IPHAN, acrescidas da demanda da presidência do órgão, a montagem de uma equipe de pesquisa destinada à tarefa foi fundamental. A COPEDOC, enquanto setor que preconizava a troca mútua entre as áreas da documentação e pesquisa, destacou a historiadora Analucia Thompson como coordenadora do Projeto, que aglutinava técnicos e estagiários como membros ativos da empreitada. 0 Arquivo Central do IPHAN-Seção RJ também dedicou esforços para as ações que se construíram de maneira coletiva e interdisciplinar. Além de historiadores, a equipe do então renomeado "Memória Oral da Preservação do Patrimônio Cultural" reunia profissionais de Arquitetura, Arquivologia, Fotografia e Museologia; houve situações em que foi decisiva, também, a participação de profissionais da COPEDOC, onde se desenvolvia o Programa de Especialização em Patrimônio (PEP).

A problemática em torno de se realizar um Projeto de Memória Oral no interior da instituição e com os próprios servidores foi debatida desde o início da segunda fase. Houve a iniciativa de consultar o CPDOC/FGV, uma das principais referências de história oral no Brasil, a respeito dos impactos metodológicos da realização de entrevistas por pessoas que pertencem ao mesmo grupo social. A constituição da equipe do projeto foi um elemento decisivo para a tomada da decisão de retomar as atividades. Isso porque o IPHAN havia acabado de realizar o seu primeiro concurso público desde a sua fundação e o ingresso de novos servidores, a partir de 2006, possibilitou que a equipe fosse constituída por profissionais que não haviam trabalhado no órgão nas décadas anteriores. Na prática, era como se os entrevistados não fossem da mesma instituição, fosse porque muitos já se haviam aposentado, fosse porque inexistia contato de trabalho anterior entre os pesquisadores e os depoentes.

Para evitar problemas de natureza metodológica, recomendou-se estabelecer o maior distanciamento possível entre a equipe do projeto e os entrevistados. A ideia era conceber uma relação apenas no momento da entrevista, de forma que as memórias pudessem ser 
construídas sem as interferências de possíveis amarras institucionais; seria o caso de viabilizar, por exemplo, os conflitos e disputas internas na instituição sem que houvesse algum fator a inibir as falas dos entrevistados. Ademais, a coordenadora do Memória Oral da Preservação do IPHAN defendeu o aspecto positivo da escolha adotada, tanto pelo registro e divulgação de experiências de agentes no e do campo do patrimônio, como por "[...] contribuir para a interação e o diálogo entre gerações dentro da Instituição" (Thompson, 2009: 9).

Um dos primeiros passos da retomada do projeto consistiu no estabelecimento formal de objetivos. 0 principal foi desenvolver a proposta de um programa de história oral destinado ao registro de entrevistas com pessoas que haviam vivido a trajetória das políticas de preservação do patrimônio cultural, tendo como referência a história institucional do IPHAN. Entre os objetivos específicos, destacaram-se: gerar acervo inédito de fontes orais com base em memórias de agentes do campo do patrimônio; disponibilizar os áudios e as respectivas transcrições das entrevistas, tanto as gravadas nos anos 1980 como aquelas realizadas nessa segunda fase do projeto; subsidiar a escrita de novas narrativas acerca do processo de constituição do campo do patrimônio cultural; e integrar a rede IPHAN, por meio das suas unidades descentralizadas em todo país, buscando parcerias técnicas a fim de viabilizar o uso da metodologia da história oral tanto no aspecto de produção de fontes como nas análises acerca das entrevistas realizadas (COPEDOC, 2008: 38).

Ancorada em Jorge Lozano (2006), a equipe optou tanto pela faceta técnica da história oral, na perspectiva de geração e disponibilização de fontes, como pelo viés metodológico, que valoriza a história oral como estratégica para a pesquisa científica e alicerçada sobre "[...] uma crítica constante realizada por pesquisadores capazes de propor, analisar e interpretar todo esse processo, visando produzir conhecimento, criticar os métodos e técnicas utilizados e rever objetivos" (Thompson, 2010: 12).

0 uso de fontes orais apresenta a possibilidade de ampliação do conhecimento sobre a história das políticas de patrimônio cultural no Brasil, pois permite o estudo das diferentes formas de articulação de atores e grupos envolvidos na construção dessas políticas, trazendo à luz a importância das ações dos indivíduos e de suas estratégias para tal. Além disso, 0 cruzamento de fontes orais e escritas, parte integrante da metodologia adotada pelo projeto, permite 0 acesso à pluralidade de narrativas sobre o passado. Essas narrativas são marcadas por especificidades em sua produção, como o fato de a entrevista ser conduzida em um contexto institucional, consistindo muitas vezes em um diálogo entre pares e colegas de instituição. A ação de rememoração do passado faz-se, portanto, em um contexto único do presente, que busca registrar diversas experiências de sujeitos em torno do tema do patrimônio cultural, destacando o sentido peculiar de cada trajetória. 
Importa frisar que o Projeto Memória Oral da Preservação se voltou, também, para a publicação da série "Memórias do Patrimônio". A ideia principal foi estruturar um tipo de produção de conhecimento que protagonizasse as entrevistas realizadas tanto nos anos 1980 como a partir de 2007. Além do conteúdo transcrito, a equipe propôs-se a escrever textos relacionados tematicamente com os depoimentos: artigos sobre as biografias dos entrevistados, análises a respeito das escolhas do Projeto propriamente dito e reflexões em torno da preservação das fontes orais no Arquivo Central do IPHAN-Seção RJ foram contemplados nas duas publicações lançadas em 2010. 0 projeto editorial ficou sob a responsabilidade de Bettina Grieco, pesquisadora da COPEDOC e integrante do Projeto Memória Oral do IPHAN desde o início da segunda fase — sua experiência foi fundamental para conferir uma linguagem dinâmica entre as fontes orais geradas pelas entrevistas e o acervo histórico do ACl-RJ, cujo resultado pode ser apreciado nas três publicações da série "Memórias do Patrimônio" 9 .

0 primeiro livro traz a entrevista com Judith Martins, realizada por Teresinha Marinho nos idos de 1982. A escolha da equipe justificou-se pelo sentido de homenagear a antiga coordenadora e os entrevistados da primeira fase do projeto, além de conceder visibilidade para a primeira das 27 entrevistas que ficaram desconhecidas pelo público mais amplo num considerável intervalo de tempo (Thompson, 2009: 12). Como uma das novidades da publicação, abriu-se uma seção denominada "Verbetes", destinada a termos retirados da própria entrevista. Ao longo da transcrição, a equipe do projeto indicou quais eram as palavras dicionarizadas; o foco dirigia-se para pessoas, lugares, instituições e bens culturais, de forma que os verbetes ficaram dispostos em ordem alfabética ao fim do livro.

A equipe do Projeto Memória Oral foi protagonista no processo de escrita dos verbetes selecionados, tendo no acervo do ACl-RJ a principal referência de pesquisa. Buscou-se, de maneira propositiva, manter uma articulação horizontal entre as fontes orais, escritas e iconográficas; a busca desse equilíbrio garantiu uma potencialidade ainda maior para as entrevistas, uma vez que elas foram valorizadas como eixos por meio dos quais se exploravam as dimensões de representatividade da escrita e da imagem. Ou seja, foi possível estabelecer redes e conexões pela oralidade, antes muito esquecida e pouco acionada nos meandros da produção de conhecimento no IPHAN.

Já o livro "Entrevista com Augusto da Silva Telles" 10 trouxe a primeira da série de entrevistas que passou a ser gravada a partir de 2007. Entrevistar Silva Telles foi encarado como experiência piloto pelos integrantes do projeto e trouxe uma série de aprendizados ao longo do processo: desde a adequada montagem do roteiro de entrevista, passando pela dinâmica das perguntas, que se adaptava às circunstâncias do momento da gravação, até a escolha dos equipamentos técnicos. Ainda que o IPHAN não proporcionasse as condições mais adequa- 
das, pode-se constatar que os padrões mínimos foram adotados, garantindo a preservação dos arquivos audiovisuais até os dias atuais.

A terceira publicação voltou-se novamente para o acervo gerado nos anos 1980; havia o objetivo de realizar um revezamento nesse sentido, ou seja, ora uma entrevista da primeira fase, ora uma narrativa colhida a partir de 2007. "Entrevista com Erich Joachim Hess" (Grieco, 2013) destacou o encontro de Teresinha Marinho e Erich Hess ${ }^{11}$ no ano de 1983.0 acervo de cerca de 5.300 fotografias produzidas pelo fotógrafo alemão para o IPHAN suscita bastante interesse por parte do público pesquisador do campo cultural. A experiência laboral de Erich Hess pode ser percebida na transcrição da entrevista que ficou por décadas inacessível, seja no olhar acurado para a diversidade arquitetônica brasileira, seja no registro dos traços dos modos de viver no interior do país.

Além da produção de conhecimento que se materializou, especialmente, nos mencionados três livros da "Série Memórias do Patrimônio", é importante sublinhar a proposta de expandir o acervo de entrevistas iniciado na década de 1980. Quando da retomada do Projeto em 2007, a COPEDOC realizou uma consulta interna com todas as unidades do IPHAN a fim de recolher sugestões de nomes para novos entrevistados. Totalizaram-se 80 nomes que foram identificados e classificados em categorias como "profissão/atuação", "local da indicação/de atuação", além de "número de indicações/faixa etária". Feita essa recolha de dados sistematizados, a equipe do Projeto debruçou-se sobre algumas variantes para escolher os entrevistados prioritários, definindo critérios como idade, número de indicações e disponibilidade de recursos para deslocamento. Além disso, havia espaço para a realização de entrevistas não listadas na consulta, por indicação da presidência do órgão ou por alguma circunstância em que elas fossem interessantes. Ainda que o ritmo de entrevistas não fosse constante, fosse pela falta de recursos, fosse pelo baixo número de integrantes na equipe, produziu-se um interessante banco de entrevistas atualmente disponível no Arquivo Central do IPHAN.

\section{PROJETO MEMÓRIA ORAL E AS TEIAS DO PATRIMÔNIO CULTURAL}

$\mathrm{O}$ ano de 2020 foi um divisor de águas no mundo dado o contexto de pandemia, como também o marco de mais um período de transição para o Projeto de Memória Oral do IPHAN. A renovação da equipe, motivada pela aposentadoria de parte de seus pesquisadores e associada à necessidade de criação de alternativas de trabalho relacionadas à modalidade remota, ensejaram uma reflexão sobre os princípios de trabalho nesse contexto e frisaram a indispensabilidade de um diálogo permanente com as ações já realizadas pelo projeto. 
Nesse sentido, a revisão de critérios e procedimentos estabelecidos em outros períodos leva-nos ao exercício de construção do que irá pautar as ações, seja com a manutenção de decisões que consideramos como acertadas e legítimas, com a ampliação ou readequação de critérios em novos contextos, seja com a inclusão de novas problemáticas que respondam a anseios colocados na conjuntura atual.

Para a elaboração dos parâmetros e fundamentos da terceira fase do projeto, então denominado "Memória Oral e Teias do Patrimônio Cultural", provemo-nos também, além da realização de um balanço da sua trajetória, da leitura de bibliografia especializada e do diálogo com projetos congêneres, que forneceram inspirações e soluções possíveis para essa nova etapa. 0 projeto, para além do "discurso autorizado de patrimônio" — que consiste em um tipo de discurso profissional que privilegia valores e conhecimentos de especialistas sobre o passado e suas manifestações materiais e domina e regula as práticas de patrimônio profissional (Smith, 2006) - intenta considerar as práticas sociais que geram o patrimônio e Ihe conferem sentido. A preservação, como toda prática, consiste em ações simbólicas, desenvolvidas em arenas ou situações sociais por sujeitos (indivíduos e instituições) guiados por motivações e estratégias referidas a sistemas de forças sociais (Arantes, 2006).

Desse modo, é possível considerar as políticas de patrimônio na perspectiva antropológica do "fazer-se Estado", e, assim, elas não estão concentradas exclusivamente nas ações do Estado, mas são compartilhadas por diversos atores - como ONG, movimentos sociais e organismos multilaterais de fomento e de cooperação técnica internacional que colaboram para as políticas, "fazendo-se Estado" (Lima e Castro, 2015). "Fazer-se Estado" implica considerar os vários agentes de preservação enquanto produtores, executores e destinatários de ações e planos governamentais de patrimônio e, assim, a história e os vínculos das ações, as articulações geradas e as reconfigurações das ações governamentais são temas privilegiados nas entrevistas do Projeto.

Novos bens passam a entrar no rol do patrimônio brasileiro e a noção de "teia", inspirada na antropologia de Tim Ingold, pode ser acessada para pensar nas práticas patrimoniais; esse autor mobiliza o conceito de "teia" e "malha" diferenciando-o da noção de "rede" tal como pensada na Teoria Ator-Rede (Latour, 2012). Para Ingold, a vida, a animacidade é uma condição de estar no mundo e poderia ser descrita por maior sensibilidade e capacidade de resposta na percepção e na ação a um ambiente que está sempre em fluxo (Ingold, 2015: 116). As práticas que não são preconcebidas são improvisadas e desenrolam-se em linhas ao longo das quais as coisas são formadas — nas palavras do autor, "a coisa, por sua vez, é um 'acontecer', ou melhor, um lugar onde vários aconteceres se entrelaçam" (Ingold, 2012: 29). Podemos pensar o estar no mundo como um emaranhado de coisas, uma teia, uma malha 
de linhas entrelaçadas de crescimento e movimento. Nesse sentido, ao contrário da rede, não existem as coisas e as conexões entre elas, mas as coisas são as relações, os entrelaçamentos, a textura do mundo. Os seres habitam o mundo num fluxo perpétuo e ao longo de caminhos. E também os seres no mundo não têm fronteiras definidas, um fechamento, eles vazam, irradiam, retomando a noção de "coisa", porosa e fluida, perpassada por fluxos vitais, integrada aos ciclos e dinâmicas da vida e do meio ambiente.

Essa perspectiva trata a produção do conhecimento também por seus aspectos vivenciais, expressivos, subjetivos, empáticos e emocionais, que podem ser restaurados à presença em processos de atenção e resposta, empreendidos também por meio das linhas formadas ao longo dos processos do Projeto Memória Oral. A ideia de teia e malha pode dar um sentido de movimento à própria perspectiva interdisciplinar, que é a premissa do Mestrado Profissional do IPHAN, no qual está baseado o Projeto de Pesquisa. Essa abertura crítica da própria ideia de interdisciplinaridade permite-nos pensar nas práticas tecidas nos cruzamentos dessas malhas disciplinares, que podem ser pensadas como "uma conversa entre companheiros de viagem seguindo linhas convergentes de interesse" (Ingold, 2020: 107).

Nesse sentido, o que se propõe é tratar a experiência dos agentes do patrimônio em questão com ênfase no que Ingold chama de "interdisciplinaridade antidisciplinar", que celebra a abertura do conhecimento por dentro, valorizando os processos contínuos de conversas por meio de linhas convergentes de interesse entre estudiosos de diferentes disciplinas, que sempre ocorreram e ocorrem nas teias do patrimônio cultural - e no IPHAN. No contexto atual do Projeto, a fim de uma maior diversificação dessas linhas de interesses convergentes relacionadas com os processos de escuta, atenção, memória e produção de relatos, buscamos uma dinamização da equipe pela consideração mais efetiva do corpo técnico da instituição. Desse modo, o acompanhamento de um projeto realizado pelo Sítio Roberto Burle Marx, Unidade Especial do IPHAN situada no Rio de Janeiro, foi o mote inspirador para pensar em ações especiais que pudessem ser iniciadas pela coordenação do grupo de "Memória Oral" e executadas por equipes locais das Superintendências e unidades regionais, de modo a se beneficiarem da característica capilar da instituição.

Nota-se que a preocupação em tratar das malhas do IPHAN já estava colocada de forma objetiva na segunda fase do projeto, e efetivou-se, por exemplo, na consulta realizada aos servidores no ano de 2007. Para esta nova fase, além da abertura para sugestões de entrevistados de modo contínuo, a ideia é ampliar essa participação para uma presença mais ativa de servidores na concepção e elaboração de temas norteadores, além da análise e realização de entrevistas. A proposta não é abandonar essa listagem, considerando-se a sua legitimidade visto que ela partiu principalmente de ampla consulta aos servidores, mas 
destrinchá-la com mais precisão, sugerindo possíveis faltas e apagamentos e refletindo sobre meios para sua ampliação.

Assim, um dos procedimentos norteadores para a realização das próximas entrevistas será a definição de linhas de interesses convergentes, buscando assim dinamizar o banco de sugestões com personagens atuantes no IPHAN e fora dele, de profissões e perfis diversos, conectados pelo assunto a ser abordado. Esse procedimento foi utilizado ao menos uma vez na segunda fase do projeto, quando nomes relacionados ao Projeto Interação ${ }^{12}$ foram relacionados e alguns efetivamente entrevistados. Essa dinâmica favorece a realização de estudos especializados, incentivando a produção de conhecimento com base em fontes orais, especialmente quando dizem respeito a ações pouco documentadas no campo do patrimônio cultural.

Nesse sentido, duas linhas de interesse convergente destacam-se na retomada dos trabalhos, tornando-se guias para as novas ações: a primeira, chamada de "Múltiplas Vozes", parte das mudanças empreendidas no campo patrimonial, com a inserção do conceito de referência cultural, da criação de novos instrumentos como o registro e a chancela da paisagem, e da necessidade de ampliar, diversificar e incluir novos sujeitos e problemáticas nesse campo; buscamos assim relatos que dialoguem com uma perspectiva mais democrática da política, de modo a reafirmar possibilidades, retomar antigos anseios e conflitos ao mesmo tempo em que documentamos as lutas e a necessidade - ainda presente — de construção de novas narrativas. Ressalta-se que esta linha pode se desdobrar em inúmeros temas, a exemplo de patrimônio indígena, patrimônio afro, patrimônio LGBTQIA+, criando assim critérios mais definidos tanto para a escolha dos entrevistados como para a posterior organização dos relatos.

A segunda linha de interesse convergente seria uma continuidade de pesquisas já realizadas no âmbito do Projeto de Memória Oral do IPHAN, a qual iremos denominar "Imagens do Patrimônio". Ao retomar o mapeamento de fotógrafos que atuaram na instituição até a década de 1980, incluído na publicação "Entrevista com Erich Joachim Hess" (Grieco, 2013), esta linha de atuação propõe-se a ampliar esses dados até os dias atuais, enfatizando a trajetória de mulheres fotógrafas e buscando também investigar o esforço de criação de novas visualidades, alternativas ao padrão concebido, divulgado e reforçado nos primeiros anos de atuação do IPHAN (Costa, 2018: 40). A ideia é articular o acervo iconográfico e documental da instituição com novas entrevistas, investigando os procedimentos investidos e ditados a esses profissionais, além de refletir sobre o papel da fotografia no IPHAN no passado e atualmente, reforçando a necessidade de construção de uma história com imagens, uma vez que estas se consolidariam como suportes de relações sociais (Mauad e Louzada, 2016: 110).

Além da estrutura por linhas de interesse e da pulverização das ações pela estrutura do IPHAN, outras preocupações conformam e balizam a nova postura, como a maior diversifica- 
ção do perfil dos entrevistados. Ao realizarmos uma rápida análise de como se configurou esse perfil nas fases anteriores do projeto por meio de dados compilados sobre as entrevistas já realizadas, podemos aferir certas constâncias, além de sugerir possíveis faltas e apagamentos. Na primeira fase do projeto, do total de 27 entrevistados, entre os quais principalmente atores que participaram ativamente do processo de consolidação do IPHAN na sua chamada "fase heroica", apenas três são mulheres, o que reverbera a escassa presença feminina na atuação do órgão nesse período, além do distanciamento delas das posições de mando.

Já na segunda fase do projeto, com base na análise da lista de sugestões consolidada em 2007, vemos que, das 16 entrevistas realizadas, apenas seis são com mulheres, o que mostra que a sub-representação feminina diminuiu, mas não acabou. Os dados compilados na lista de sugestões nos permitem também auferir características do perfil profissional dos entrevistados: oito são arquitetos e arquitetas e há também dois professores, dois jornalistas, uma historiadora, uma artista plástica, um arquivista e um administrador. Ampliando o olhar para a lista geral de sugestões, dos 87 nomes compilados, 44 são formados em Arquitetura e Urbanismo. A prevalência de uma profissão que, durante um período, foi a responsável por ditar os critérios de seleção e as características do que seriam o patrimônio nacional (Chuva, 2017: 211) não corresponderia à diversidade de instrumentos e ações realizadas no campo hoje, que demanda uma variedade profissional muito maior que a apresentada. Apesar desses primeiros apontamentos, os dados compilados nessa listagem não permitem apreender uma série de pontos fundamentais no debate contemporâneo, como por exemplo a questão étnico-racial, mas que devem ser levados em conta na definição dos critérios das entrevistas nesta terceira fase.

Outra questão que define sobremaneira a continuidade do projeto nos dias atuais é a situação de pandemia de COVID-19 que, no momento em que escrevemos, completa mais de um ano. Soma-se à necessidade de isolamento social a falta de recursos para as ações institucionais, que impactam de modo negativo questões efetivas, como a impossibilidade de deslocamento para a realização de entrevistas e a falta de verba para publicações. Entretanto, é um cenário que favorece, a exemplo do que fazem outros pesquisadores, a adoção de procedimentos como a realização de entrevistas por meio remoto, anteriormente visto com ressalvas no campo da História Oral (Santhiago e Magalhães, 2020: 2).

No contexto contemporâneo de mudanças nas nossas relações de sociabilidade, a história oral instiga-nos a buscar novas alternativas para que o processo de pesquisa e de produção do conhecimento permaneça e se reinvente. Partindo dos procedimentos e dos princípios colocados neste artigo, buscamos ressaltar a importância da oralidade nos processos de preservação do patrimônio cultural. Seja com base nas entrevistas realizadas nos 
processos de identificação e produção de conhecimento a respeito dos bens culturais materiais e imateriais, seja pensando no caráter peculiar dos relatos de trajetórias de agentes do patrimônio que formam o acervo do projeto, buscamos não apenas dar continuidade à pesquisa, como também dinamizá-la e atualizá-la perante as problemáticas contemporâneas no campo do patrimônio cultural.

Conflitos de interesse: nada a declarar.

Fonte de financiamento: nenhuma.

Contribuições dos autores: Gervásio, F.; Pereira Filho, H.; Brandão, J.: Análise Formal, Curadoria de Dados, Escrita - Primeira Redação, Escrita - Revisão e Edição.

\section{NOTAS}

1 Nascido no Recife/PE, formou-se em Direito, porém suas atividades profissionais ligaram-se à tipografia e ao teatro após bolsa de estudos em Paris. A partir dos anos 1960 concentrou interesses na área de Comunicação Visual e Design, passando a expor em galerias por todo mundo. Um dos criadores do Centro Nacional de Referência Cultural (CNRC), recebeu o convite para presidir o IPHAN em 1979, quando houve a criação da Fundação Nacional Pró-Memória, espécie de braço executivo da então SPHAN. A gestão de Aloísio Magalhães realizou ações inovadoras no campo do patrimônio cultural para além da materialidade dos bens tombados, articulando noções como cultura, indústria, comércio e turismo.

2 Nascido em Belo Horizonte/MG, formou-se em Direito no Rio de Janeiro/RJ, onde desenvolveu suas atividades profissionais. Participou do movimento modernista na década de 1920 e, nos idos de 1936, foi nomeado para organizar o SPHAN durante a gestão de Gustavo Capanema à frente do Ministério da Educação e Saúde. Diretor do IPHAN entre os anos de 1937 e 1967, a gestão de Rodrigo Melo Franco de Andrade foi marcada pelo estabelecimento e a consolidação das políticas públicas de patrimônio no Brasil, em diálogo com práticas preservacionistas internacionais.

3 Judith Martins ingressou nos primórdios do IPHAN e seu trabalho de secretariado foi decisivo para as tomadas de decisões do gabinete do primeiro diretor do órgão, Rodrigo Melo Franco de Andrade. Formada em História da Arte, foi pesquisadora, escritora e chefe da Seção de História e Arquivo, além de autora de livros como "Dicionário de artistas e artífices dos séculos XVIII e XIX em Minas Gerais". 
4 Imigrante alemão, naturalizou-se brasileiro em 1933 e era monge da Ordem Beneditina Brasileira. A convite de Rodrigo Melo Franco de Andrade, foi acionado para realizar pesquisas históricas em acervos documentais de interesse do IPHAN, além de desempenhar atividades de perícia em Belas Artes.

5 Museóloga de referência internacional, iniciou suas atividades como conservadora do Museu Nacional de Belas Artes. Ingressou no IPHAN durante a década de 1950, colaborando na organização de novos museus da instituição. Foi chefe da Divisão de Estudos e Tombamento do IPHAN por mais de 20 anos. Mesmo após a aposentadoria, no início dos anos 1990, produziu relevantes estudos técnicos na Museologia.

6 Formado em Arquitetura pela antiga Universidade do Brasil, foi convidado para trabalhar no IPHAN em 1944. A partir de então, dedicou-se a trabalhos de inventário e restauração em conjuntos urbanos dos estados de Goiás, Minas Gerais, Rio de Janeiro e São Paulo por intermédio das representações regionais do órgão.

7 Arquiteto de formação, interessou-se pela pintura artística quando se aproximou de Cândido Portinari. Convidado para trabalhar no IPHAN a partir da década de 1940, dedicou-se à conservação de bens culturais localizados em Minas Gerais, além de ter participação constante junto à direção do órgão no Rio de Janeiro.

8 Formado em Pintura e Arquitetura pela Escola Nacional de Belas Artes, Lucio Costa assumiu a docência ainda nos anos 1930. A interlocução com o arquiteto Le Corbusier foi fundamental para construir novas perspectivas de olhares sobre o modernismo. Ingressou no IPHAN em 1937, a convite de Rodrigo Melo Franco de Andrade, onde chefiou a Divisão de Estudos e Tombamento até sua aposentadoria em 1972. Notabilizou-se por várias obras, em especial o projeto do Plano Piloto para a nova capital Brasília/DF, além de valorizar o estilo barroco como uma das grandes marcas do patrimônio edificado brasileiro.

9 Disponíveis em: <http://portal.iphan.gov.br/uploads/publicacao/SerMemPat_MemoriasPatrimonio_EntrevistaJudithMartins.pdf >; <http://portal.iphan.gov.br/uploads/publicacao/ SerMemPat_MemoriasPatrimonio_EntrevistaErichJoachimHess.pdf>; $\quad<$ http://portal.iphan. gov.br/uploads/publicacao/sermempat_memoriaspatrimonio_entrevistasilvatelles_m.pdf>. Acesso em: 3 ago. 2021.

10 Conhecido como Silva Telles, desempenhou atividades de arquiteto do IPHAN por mais de cinco décadas, desde os anos 1940. Ocupou vários cargos de direção no órgão e foi referência para muitos no campo do patrimônio, tanto pela carreira docente na antiga Faculdade Nacional de Arquitetura como pela fundação do Comitê Nacional do Conselho Internacional dos Monumentos e Sítios e pelas participações no Conselho Consultivo do IPHAN. 
11 Imigrante alemão, chegou ao Brasil pouco antes da Segunda Guerra Mundial. Erich Hess trabalhou no IPHAN como fotógrafo.

120 Projeto Interação surgiu no âmbito de ações desenvolvidas no CNRC e consistia "no apoio à criação e ao fortalecimento das condições necessárias para que o trabalho educacional se produzisse referenciado na dinâmica cultural, reafirmando a pluralidade e a diversidade cultural brasileira" (IPHAN, 2014: 9).

\section{REFERÊNCIAS BIBLIOGRÁFICAS}

ALBERTI, V. O que documenta a fonte oral? Possibilidades para além da construção do passado. In: SEMINÁRIO DE HISTÓRIA ORAL, 2., 1996, Belo Horizonte. Anais [...]. Belo Horizonte: UFMG, 19 a 20 set. 1996. p. 1-13. [Trabalho apresentado à mesa-redonda "Ouvir e narrar: métodos e práticas do trabalho com História Oral"]. Disponível em: <http://cpdoc.fgv.br/producao_intelectual/arq/869.pdf>. Acesso em: 14 jul. 2021.

ARANTES, A. A. 0 patrimônio cultural e seus usos: a dimensão urbana. Habitus, Goiânia, v. 4, n. 1, p. 425-435, 2006. http://dx.doi.org/10.18224/hab.v4.1.2006.425-435.

CHUVA, M. R. R. Os arquitetos da memória: sociogênese das práticas de preservação do patrimônio cultural no Brasil (anos 1930-1940). Rio de Janeiro: UFRJ, 2017.

COPEDOC - Coordenação-Geral de Pesquisa e Documentação do Instituto do Patrimônio Histórico e Artístico Nacional. Relatório de Atividades da Coordenação-Geral de Pesquisa e Documentação do Instituto do Patrimônio Histórico e Artístico Nacional (COPEDOC/IPHAN). Rio de Janeiro: COPEDOC, 2008.

COSTA, E. Arquivo, poder, memória: Herman Hugo Graeser e o Arquivo Fotográfico do IPHAN. São Paulo: Alameda, 2018.

FERREIRA, M.; AMADO, J. (orgs.). Usos e abusos da História Oral. Rio de Janeiro: FGV, 2006.

GRIECO, B. Z. (org.). Entrevista com Erich Joachim Hess. Rio de Janeiro: IPHAN/DAF/COPEDOC, 2013.

HALBWACHS, M. A memória coletiva. São Paulo: Editora Vértice, 1990.

INGOLD, T. Trazendo as coisas de volta à vida: emaranhados criativos num mundo de materiais. Horizontes Antropológicos, Porto Alegre, v. 18, n. 37, p. 25-44, 2012. https://doi.org/10.1590/S010471832012000100002.

INGOLD, T. Estar vivo: ensaios sobre movimento, conhecimento e descrição. Petrópolis: Vozes, 2015.

INGOLD, T. Antropologia e/como educação. Petrópolis: Vozes, 2020.

IPHAN - Instituto do Patrimônio Histórico e Artístico Nacional. Educação patrimonial: histórico, conceitos e processos. Brasília, DF: IPHAN, 2014.

LATOUR, B. Reagregando o social: uma introdução à teoria do ator-rede. Bauru: Salvador: EDUSC; EDUFBA, 2012.

LIMA, A. C. S.; CASTRO, J. P. M. Notas para uma Abordagem Antropológica da(s) Política(s) Pública(s). Revista Anthropológicas, Recife, v. 26, n. 2, p. 17-54, 2015. https://doi.org/10.51359/2525-5223.2015.23968. 
LOZANO, J. Prática e estilos de pesquisa na história oral contemporânea. In: FERREIRA, M.; AMADO, J. (orgs.). Usos e abusos da História Oral. Rio de Janeiro: FGV, 2006. p. 15-25.

MARINHO, T. (coord.). Depoimento de D. Clemente da Silva Nigra. Rio de Janeiro: MinC/SPHAN/FNPM, 1985. (Memória Oral, n. 5).

MARINHO, T. Entrevista concedida ao Projeto Memória Oral da Preservação do Patrimônio Cultural. Rio de Janeiro: 15 abr. 2009.

MAUAD, A. M.; LOUZADA, S. Com palavras e imagens se conta a história. In: MAUAD, A. M. (org.). História oral e mídia: memórias em movimento. São Paulo: Letra e Voz, 2016. p. 93-111.

ROUSSO, H. $O$ arquivo ou o indício de uma falta. Revista Estudos Históricos, Rio de Janeiro, v. 9, n. 17, p. 1-7, 1996.

SANTHIAGO, R.; MAGALHÃES, V. Rompendo o isolamento: reflexões sobre história oral e entrevistas à distância. Anos 90 - Revista do Pós-Graduação em História, Porto Alegre, v. 27, e2020011, 2020. https:// doi.org/10.22456/1983-201X.102266.

SMITH, L. Uses of heritage. New York: Routledge, 2006.

THOMPSON, A. (org.). Entrevista com Judith Martins. Rio de Janeiro: IPHAN/DAF/COPEDOC, 2009.

THOMPSON, A. (org.). Entrevista com Augusto Carlos da Silva Telles. Rio de Janeiro: IPHAN/DAF/COPEDOC, 2010. 